Penultimate version-forthcoming in Ethics

\title{
Contrastive Reasons and Promotion
}

\author{
Justin Snedegar \\ University of St Andrews \\ js280@st-andrews.ac.uk
}

September 13, 2013

\section{Introducing Contrastivism}

Frequently, whether a consideration is a reason to perform some action depends on what we are comparing that action to. Consider the following case, borrowed from Sinnott-Armstrong (2006). Today is my friend Julia's birthday. This is a reason for me to bake her a chocolate cake rather than bake her a meatloaf, given the birthday conventions of our society. But it's not a reason for me to bake her a chocolate cake rather than bake her a lemon cake. Similarly, the fact that the library book is due back today is a reason for me to take it back to the library rather than leave it on my shelf. But this fact is not a reason for me to take it back to the library rather than send it with you on your trip to the library.

So it seems as if whether the fact that it's Julia's birthday is a reason to bake her a chocolate cake, or the fact that the book is due back today is a reason to take it to the library, depends on what we're comparing those actions to. The traditional view that considerations are reasons for actions independently of what we're comparing the actions to has trouble explaining this observation. ${ }^{1}$ Instead, these cases support the view I will be concerned with in this paper, which I'll call contrastivism about reasons. This is the view that considerations are always reasons for one thing rather

\footnotetext{
${ }^{1}$ This assumption of non-contrastivity is not made explicit - it is rather assumed without argument. But see, for a very small sampling, Nagel (1970), who gives a non-contrastive definition of a reason, Scanlon (1998), who claims that a reason is a consideration that counts in favor of something, without mentioning alternatives, and Schroeder (2007), who holds that a reason is a fact that explains why performing some action would promote the satisfaction of one of the agent's desires, again without mentioning alternatives.
} 
than another, or for one thing out of a range of alternatives, instead of reasons for things simpliciter. ${ }^{2}$

According to contrastivism, the fact that it is Julia's birthday is a reason to bake her a chocolate cake relative to \{bake her a chocolate cake, bake her a meatloaf\}, but not relative to $\{$ bake her a chocolate cake, bake her a lemon cake\}. This provides a straightforward explanation of these otherwise puzzling cases. The solution to this problem depends on the fact that, according to the contrastivist, reasons relative to different sets of alternatives may be independent of one another, in the following sense. Some consideration may be a reason to $A$ relative to one set without being a reason to $A$ relative to some other set. ${ }^{3}$

This simple argument is not enough to establish contrastivism, since the noncontrastivist can try to analyze these 'rather than' ascriptions in terms of noncontrastive reasons. To take just one example, a natural non-contrastivist response is that ' $r$ is a reason for $A$ rather than $B$ ' just means that $r$ is a stronger reason for $A$ than it is for $B$. This would allow the non-contrastivist to explain cases like those above. But this response is problematic: it relies on an ad hoc treatment of 'rather than'. In other uses, 'rather than' means something along the lines of 'and not', and nothing like 'stronger than'. There are other potential responses, but as I argue in Snedegar (fc), many natural responses are problematic. The goal here, though, is just to illustrate contrastivism, so I will not say more about this simple argument.

The cases above illustrate one feature of contrastivism, which I will call nonexhaustivity: reasons are relativized to sets of alternatives that are not necessarily exhaustive of all of the options open to the agent. Even if it is open to me to bake Julia a chocolate cake, to bake her a lemon cake, and to bake her no cake at all, we can simply talk about my reasons relative to, say, \{bake a chocolate cake, bake a lemon cake\}, that is, my reasons to bake her a chocolate cake rather than a lemon cake, or to bake her a lemon cake rather than a chocolate cake. The second important feature of contrastivism is what I will call (following Yalcin (2011) and Cariani (2013)) resolution-sensitivity: different sets will divide up possibilities in more or less fine-grained ways - at higher and lower resolutions. For example, a particularly coarse-grained set is \{bake a chocolate cake, do not bake a chocolate cake\}. A more fine-grained set is \{bake a German chocolate cake, bake a chocolate mousse cake,

\footnotetext{
${ }^{2}$ Other authors who have endorsed contrastivism more or less explicitly include Norcross (2005), Ross (2006), chapter 9, and especially Sinnott-Armstrong (2004, 2006, 2008).

${ }^{3}$ We can make perfectly legitimate non-contrastive reason ascriptions, like 'The fact that it's Julia's birthday is a reason to bake her a chocolate cake', of course. But according to the contrastivist, we have to understand these as implicitly contrastive. See Snedegar (fc).
} 
bake a lemon cake, bake a meatloaf, don't bake anything\}. Later in the paper, in section 3.5, I will present a case that motivates relativizing reasons to sets that can differ in resolution. ${ }^{4}$

I have introduced one simple application for contrastivism about reasons, and there are several others. ${ }^{5}$ However, while contrastivism solves some problems, it creates others. In particular, other contrastivists have not recognized that the independence of reasons relative to different sets - the key to securing the advantages of contrastivism - leads to a serious problem. The problem is simply that the contrastivist threatens to make reasons relative to different sets objectionably independent of one another. There should be some constraints on this independence: knowing about the reasons relative to one set should tell us something about the reasons relative to certain other sets. For example, if some consideration is a reason for $A$ rather than $B$, and a reason for $B$ rather than $C$, then surely it should be a reason for $A$ rather than $C$. But for all that has been said so far, nothing about contrastivism constrains the independence of reasons relative to different sets in any way. Thus, contrastivism seems to lack a principled way to guarantee this kind of transitivity.

In the next section, I will present this problem in detail, describing other constraints that the contrastivist seems unable to provide. In the remainder of the paper, I develop a version of contrastivism that solves this problem. My solution is to appeal to the widespread idea that (at least many) reasons involve the promotion of various kinds of objectives, including the satisfaction of desires, the attainment of goals, and the realization or instantiation of values. This idea itself independently motivates a particular version of contrastivism, because, as I argue in section 3, the best way to make sense of the relationship between reasons and promotion is on a contrastive framework. And this independently motivated version of contrastivism

\footnotetext{
${ }^{4} \mathrm{~A}$ common concern about contrastivism stems from the idea that there has to be something that we really have reason to do, not just what we have reason to do relative to some set. While I cannot address this issue fully here, I do want to say something to mitigate this concern. It is compatible with the contrastivist picture that some reasons - moral reasons are a good candidateare relativized to sets that are special in some way. For example, these sets may be exhaustive of all the options open to the agent, divided up in a maximally fine-grained way, or in a way that only differentiates between possibilities when there is a moral difference between them. So it may differentiate between 'run to save the child' and 'stand on the shore and watch', but not between 'run to save the child left-foot-first' and 'run to save the child right-foot-first'. I think examples like the one above motivate thinking that not all reasons are relativized to exhaustive sets, and cases that I will consider below motivate thinking that reasons should be relativized to sets that can differ in resolution. But, again, this is perfectly compatible with thinking that some reasons are relativized to special kinds of sets. See Kierland (ms) for a contrastive view of obligation in this vein. Thanks to an anonymous referee for stating this worry in a particularly explicit way.

${ }^{5}$ For others, see Snedegar (2013).
} 
straightforwardly generates an elegant solution to the problem from section 2 by providing just the right constraints on the independence of reasons relative to different sets of alternatives. I develop the theory in section 4, providing analyses of reasons for and against in terms of promotion, and show that this view provides the constraints in section 5. The moral is that a compelling independent source of motivation for contrastivism leads directly to a version of the theory that solves a pressing problem for the contrastivist.

\section{A Problem for the Contrastivist}

The contrastivist gains advantages over the traditional non-contrastive picture by making reasons relative to different sets of alternatives independent of one another. The problem I introduced above, and will spell out below, is that this independence needs to be constrained in certain ways, but the contrastivist seems to have no way to do this. Moreover, she must be careful in trying to solve this problem, so that she doesn't constrain the independence of reasons relative to different sets so much that she loses advantages over the non-contrastive picture.

\section{$2.1 \quad$ Intransitivity}

Suppose I want to get in shape. Then the fact that physical exertion helps one get in shape is a reason to jog to Cafe 101 for my daily milkshake, rather than walk there. Similarly, it's a reason to walk there rather than drive. Is it a reason to jog rather than drive? Of course. And any plausible theory of what makes some consideration a reason for one thing rather than another will say so.

But the important thing to notice for my purposes here is that we shouldn't have to think about this at all, once we know it's a reason to jog rather than walk, and a reason to walk rather than drive. It should just follow that it's a reason to jog rather than drive. More generally, if $r$ is a reason for $A$ rather than $B$ and a reason for $B$ rather than $C$, it should simply follow that $r$ is a reason for $A$ rather than $C$. To deny this is to allow for a very troubling kind of intransitivity. ${ }^{6}$

The problem for the contrastivist is that nothing about the theory, for all that's

\footnotetext{
${ }^{6}$ This isn't the same kind of intransitivity that receives a lot of attention in the literature, the intransitivity of 'better than' or 'more reason than'. See especially Temkin (1987, 2012); Rachels (1998, 2001); Friedman (2009) for advocates; see, for example, Broome (1991) for defense of the much more common view that intransitivity is impossible. Nevertheless, the sort of intransitivity at issue here does seem problematic, as well.
} 
been said, seems to rule out this kind of intransitivity. Since reasons relative to different sets can be independent of one another - as they need to be for contrastivism to gain advantages over non-contrastive theories - we have no reason to think that the reason relation will guarantee that reasons for $A$ rather than $B$ and for $B$ rather than $C$ will be reasons for $A$ rather than $C$. Ruling out this intransitivity is one important constraint.

\subsection{Reasons for and subsets}

The fact that Bill has high blood pressure is a reason for him to order fish out of \{order fish, order pork, order beef\}. ${ }^{7}$ If the waiter comes back to the table and tells Bill that the restaurant is out of pork, or ordering pork becomes irrelevant for some other reason, that obviously shouldn't change this: the fact that he has high blood pressure is still a reason to order fish out of \{order fish, order beef $\}$. And again, any plausible theory about what makes a consideration a reason for an action out of a set of alternatives will say so.

But again, the important point is that we shouldn't have to think about this at all. It should just follow that, in general, when $r$ is a reason for $A$ out of $\{A, B, C\}$, it's also a reason for $A$ out of $\{A, B\}$. Even more generally, reasons for an alternative out of one set should also be reasons for that alternative out of arbitrary subsets that include the alternative. If $r$ is a reason for $A$ when some other option $B$ is relevant, making $B$ irrelevant should not change this.

At this point, I want to briefly diverge from the main thread to discuss an apparent counterexample to this entailment relation. I do so because seeing why it is not in fact a counterexample helps clarify the main contrastivist thesis by distinguishing it from a more widely-held thesis. Suppose you want to pick the brightest color from a range of colors in front of you: A, B, and C. Due to features of our visual system, in the presence of $\mathrm{C}$, A appears brighter than B. But if $\mathrm{C}$ is not present, A does not look brighter than B. Thus, it seems that your goal of picking the brightest color gives you a reason to choose $\mathrm{A}$ out of $\{$ choose $\mathrm{A}$, choose $\mathrm{B}$, choose $\mathrm{C}\}$, but does not give you a reason to choose $\mathrm{A}$ out of $\{$ choose $\mathrm{A}$, choose $\mathrm{B}\}$.

To see why this is not in fact a counterexample to the entailment relation, we need to distinguish between the variability of reasons with the relevant alternatives, or with the contrasts, and the variability of reasons with the circumstances of choice. The circumstances of choice may include various things, but for my purposes here, the most

\footnotetext{
${ }^{7} \mathrm{I}$ 'm assuming that these alternatives are mutually exclusive-Bill can order at most one of the dishes.
} 
important things they include are features of the environment. In particular, in this example, the presence or absence of color $\mathrm{C}$ will be part of the circumstances. Many philosophers hold that the circumstances of choice can affect what reasons there are. ${ }^{8}$ On the other hand, the central thesis of contrastivism is that reasons can vary not (only) with the circumstances, but (also) with the contrasts - the alternative actions we are comparing. The entailment relation, that reasons for $A$ out of $Q$ are also reasons for $A$ out of subsets of $Q$ that contain $A$, concerns shifts in the contrasts, not the circumstances. So the entailment only holds as long as we hold the circumstances fixed. Thus, we need to hold the presence or absence of color $\mathrm{C}$ fixed. If we assume that $\mathrm{C}$ is present, then color $\mathrm{A}$ will appear brighter than color B. So you will not only have a reason to choose $\mathrm{A}$ out of $\{$ choose $\mathrm{A}$, choose $\mathrm{B}$, choose $\mathrm{C}\}$, but also out of $\{$ choose $\mathrm{A}$, choose $\mathrm{B}\}$-again, since $\mathrm{C}$ is present $\mathrm{A}$ will look brighter than $\mathrm{B}$. We have removed choosing $\mathrm{C}$ as a relevant alternative, but have not removed the presence of $\mathrm{C}$ as part of the circumstances. So the entailment relation survives this apparent counterexample.

\subsection{Reasons against and supersets}

Now suppose the fact that Bill has high blood pressure is a reason against ordering beef out of \{order fish, order pork, order beef $\}$. If the waiter comes back and informs Bill that the restaurant also has a salad, he shouldn't have to reconsider whether the fact that he has high blood pressure is a reason against ordering beef. Adding a new relevant alternative shouldn't change this. In general, reasons against an alternative out of one set are intuitively reasons against that alternative out of supersets of that set. 9

${ }^{8}$ Dancy (2004)'s holism about reasons is a particularly clear statement of this thesis, but again, I think it is widely held.

${ }^{9}$ Apparent counterexamples to this constraint (which can be amended to target either of the other constraints I've discussed) involve cases in which learning about the new option gives the agent new information about the old options. So for example, Bill may know that the restaurant only serves salad on nights when Chef Jack Sprat is working, and that Chef Sprat prepares beef in a heart-healthy way. Thus, upon learning that the restaurant is serving salad, it seems that the fact that he has high blood pressure is not a reason against ordering the beef, since the beef is actually heart-healthy. I'll offer two replies. First, what has changed here is Bill's information; this may make it so that he no longer has a subjective reason, or a reason relative to his information, against ordering beef. But it is no surprise that Bill's subjective reasons can change with his information; the constraints are just meant to hold relative to the same body of information. But Bill's objective reasons have not changed - since Chef Sprat is in the kitchen, there was never actually any objective reason against ordering the beef (at least not one related to Bill's blood pressure). Second, if we don't like the distinction between objective and subjective reasons, we could simply adopt a more fine-grained view of the options: 'order beef when Chef Sprat makes it' is a different option than 'order beef when Chef Sprat's wife makes it', or 'order beef when salad is available' is different 


\subsection{Entailment relations and deliberation}

These and other intuitive entailment relations should hold between reasons relative to different but related sets. ${ }^{10}$ I have motivated this thought by describing examples in which violation of these entailments seems crazy. The more general idea, which these cases are meant to bring out, is the following. Reasons are used in deliberating about what to do - a central sort of deliberation involves weighing up reasons for and against various options. Often, this deliberation takes place over time, and as time passes, the alternatives we are considering can shift in various ways. Alternatives that were initially irrelevant may become relevant, or vice versa, for example. Since the contrastivist holds that reasons shift as the relevant alternatives shift, it seems that she is committed to saying that the reasons to be used in deliberation can shift. Thus, if the alternatives shift, it seems that the agent will have to abandon the results of her previous deliberation - those reasons aren't in play anymore. This would make crosscontext deliberation impossible. But of course it is not impossible. What the cases I've described are meant to bring out is that there are constraints on how the reasons can shift as the alternatives shift. Even if some of an agent's reasons shift as the relevant alternatives shift, others do not. This is the problem facing the contrastivist that I'll attempt to solve in the remainder of the paper.

\section{Promotion}

In this section, I'll argue that the popular idea that reasons are intimately related to the promotion of some kind of objectives - the satisfaction of desires, the realization of values, and so on - supports contrastivism. I mean for 'objectives' to be a technical term, standing for whatever it is that is to be promoted on these sorts of theories. I'll raise problems for non-contrastive views that contrastivism avoids; these problems do not necessarily prove conclusively that all non-contrastive theories are false, but they do provide independent support for the version of contrastivism I will develop in the rest of the paper.

than 'order beef when salad is not available', or 'order heart-healthy beef' is different than 'order heart-unhealthy beef'. Thanks to Ephraim Glick and Don Hubin for calling my attention to these kinds of cases, which are common in the decision theory literature.

${ }^{10}$ I'll say more about entailments between sets that differ in resolution in section 5 . 


\subsection{Promotion in the theory of reasons}

Several writers with importantly different views about the nature of normative reasons accept something like the following schema:

Promote: There is a reason for $s$ to $A$ iff $s$ 's $A$-ing would promote some $X$ of the relevant kind.

Some writers, like Moore (1903, 1912); Wedgwood (2009); Parfit (2011) take the Xs to be objective values, like happiness or justice. ${ }^{11}$ Others, like Schroeder (2007), take the relevant kind of $X$ to be the objects of the desires of the agent. And others, like Finlay $(2006, \mathrm{~ms})$, take the relevant kind of $X$ to be contextually-specified ends. Nagel (1970) also analyzes reasons in terms of promotion, though his view is importantly different. Still, there is a plausible view in the neighborhood of Nagel's which fits Promote. ${ }^{12}$

Writers like Scanlon (1998) and Anderson (1993) draw a distinction between promoting values and respecting or honoring values. If we make this distinction, we might worry that some reasons will not be explained by, or even involve, the promotion of anything. For example, according to this view, the value of friendship primarily gives us reasons to do things that would respect or honor friendships, say treating our friends well, rather than things that would promote friendship, say matching up people we think would make good friends. ${ }^{13}$ The argument for contrastivism that I will give shortly is that the idea that reasons involve promotion is best captured on a contrastive theory. If not all reasons involve promotion, then this argument at best would seem to show that some reasons - those that involve promotion - are contrastive. But contrastivism, as I want to defend it, is the thesis that all reasons are contrastive.

I think we can allow that some reasons do not involve promotion, but rather involve respecting or honoring values, without limiting the scope of contrastivism in this way. Everyone should recognize that at least some reasons involve promotion. ${ }^{14}$

\footnotetext{
${ }^{11}$ Moore talked about rightness rather than reasons, but his view of rightness would extend straightforwardly to this kind of view of reasons.

${ }^{12}$ The complication with Nagel's view is that he thinks what we have reasons to do is to promote valuable states of affairs, whereas the other theories hold that the fact that performing certain actions would promote certain objectives is what explains why we have reasons to do those actions. So on Nagel's view, the concept of promotion shows up in what we have reason to do, while on the other views, it shows up in the account of what it is for some fact to be a reason for us to perform some action.

${ }^{13}$ See Pettit (1991) and Pettit's contribution to Baron et al. (1997) for a defense of the view that all reasons involve promotion.

${ }^{14}$ For example, instrumental reasons to take the means to our ends seem to be clearly tied to the promotion of those ends. See Kolodny (ms); Bedke (ms) for relevant discussion.
} 
And if I am right that these reasons are contrastive, that is some pressure to adopt contrastivism about all reasons. It is theoretically unattractive to posit two separate reason relations, one of which is contrastive and one of which is non-contrastive. If there is a plausible unified view of reasons on offer, that would be preferable.

I will develop my contrastive theory in terms of promotion, since (i) everyone should agree that some reasons involve promotion, and (ii) doing so will simplify exposition of the view. At the end of the paper, however, I will return to this point and show how to generalize the view to cover non-promotional reasons.

Here is an important question at this point: what is it to promote an objective? One natural and popular answer is that your $A$-ing promotes an objective $X$ when it raises the probability of $X$. Several authors have understood promotion in probabilistic terms. ${ }^{15}$ So, for example, promoting the satisfaction of a desire is simply making it more probable that the desire is satisfied, promoting the realization of a value is making it more probable that the value is realized or instantiated, and so on. You may be wondering at this point, 'More probable than what?'. It will emerge shortly that I think this is a crucial question. Even so, though, this is a plausible, if not extremely informative, way of understanding promotion. Nevertheless, the idea that the relevant kind of promotion is probabilistic is controversial. Though many writers are tempted by this sort of probability-raising view, others doubt that reasons can be helpfully analyzed in terms of probabilities. ${ }^{16}$ Fortunately, my project here does not depend on any particular view about what it is to promote an objective. Before moving on to argue against various non-contrastive theories, I will just list some structural properties that I will assume the relevant kind of promotion has. It will be clear that a probability-raising analysis of promotion will have these properties, but I will not assume such an analysis.

We are interested in determining whether performing a given action promotes a given objective. The first assumption I will make is that the relevant kind of promotion ranks actions in terms of how well they promote the objective. Different objectives will of course give us different rankings: $A$-ing may better promote objective $X$ than $B$-ing, while $B$-ing better promotes objective $Y$ than $A$-ing. These rankings may allow for both ties and incommensurability. But I do assume that the ranking is transitive: if $A$ better promotes $X$ than $B$, and $B$ better promotes $X$ than $C$, then $A$ better promotes $X$ than $C$. (In formal terms, I will assume that a given

\footnotetext{
${ }^{15}$ See Finlay (2006, ms); Schroeder (2007); Kolodny (ms); Bedke (ms) for different versions of this idea.

${ }^{16}$ See Wedgwood (2009), for example.
} 
objective partially orders actions in terms of how well they promote the objective.) I will not argue for this property here. But I do think that this is a pretty minimal assumption. Moreover, the popular probability-raising view of promotion will have this property. We can rank actions in terms of how much they raise the probability of the objective. And if $A$ raises the probability of $X$ more than $B$, and $B$ raises the probability of $X$ more than $C$, then $A$ will raise the probability of $X$ more than $C$, since 'greater than' is transitive.

The second assumption I will make is that this ranking will have what I call the Disjunction Boundedness property:

Disjunction Boundedness: For all actions $A$ and $B$ and for all objectives $X, A \vee B$ is ranked somewhere between (inclusive) $A$ and $B$, in terms of how well it promotes $X$.

This property is less familiar than the ranking property I introduced in the last paragraph. But again, I think it is very plausible that any reasonable understanding of the relevant kind of promotion will have this property. Doing $A \vee B$ cannot do more than both $A$ and $B$ to help bring about an objective, and similarly it cannot do less than both. The probability-raising understanding of promotion has this property. ${ }^{17}$

Now I will discuss some non-contrastive views about the relationship between promotion and reasons. I will argue that all of them are problematic, which motivates my contrastive theory. ${ }^{18}$

\subsection{Doing nothing}

The first view I'll consider is offered by Schroeder (2007), p. 113:

Doing Nothing: $s$ has a reason to $A$ provided by objective $X$ iff $s$ 's $A$-ing would promote $X$ better than $s$ 's doing nothing would.

One important question for this view is what it is to do nothing. But the central problem, raised by Evers (2009), is that no matter how we understand doing nothing, it seems that there will be possible cases in which agents have reasons to do nothing.

\footnotetext{
${ }^{17}$ It is a fact about conditional probabilities that when $P(X \mid A) \geq P(X \mid B), P(X \mid A) \geq P(X \mid A \vee$ $B) \geq P(X \mid B)$. So doing $A \vee B$ cannot make $X$ more probable than doing $A$ or less probable than doing $B$.

${ }^{18}$ The non-contrastive views I will consider were originally offered in probabilistic terms, but I will abstract away from this and just discuss them in terms of a more abstract notion of promotion. This is fine for my purposes, since I am interested in what these views say about the relationship between promotion and reasons, not in the particular way they understand promotion.
} 
For example, doing nothing may just be maintaining the status quo (this is at least suggested by Schroeder). But sometimes we have reasons to simply maintain the status quo; similar remarks go for other natural ways of understanding what it is to do nothing. But it is easy to see that this view rules this out: for me to have a reason to do nothing, according to this view, my doing nothing would have to better promote some objective than my doing nothing would. And of course this is impossible.

\subsection{Not $A$-ing}

The second view I will consider is offered by Finlay (2006, ms):

Not $A$ : $s$ has a reason to $A$ provided by $X$ iff $s$ 's $A$-ing better promotes $X$ than $s$ 's not $A$-ing.

This account allows for reasons to do nothing: you can have such a reason as long as your doing nothing promotes some objective better than not doing nothing. But to evaluate this account, we need to know what not $A$-ing is. Here are three options:

Possibilism: $s$ has a reason to $A$ provided by $X$ iff $s$ 's $A$-ing better promotes $X$ than everything else $s$ could do.

Actualism: $s$ has a reason to $A$ provided by $X$ iff $s$ 's $A$-ing better promotes $X$ than whatever it is $s$ would actually do, if she $\operatorname{did}$ not $A$.

Probabilism: $s$ has a reason to $A$ provided by $X$ iff $s$ 's $A$-ing better promotes $X$ than $s$ 's not $A$-ing, where the degree to which $s$ 's not $A$-ing promotes $X$ is a function of (i) the degree to which $s$ 's $B$-ing promotes $X$, and (ii) the probability that $s$ will perform $B$, for each alternative $B$ incompatible with $A$.

Possibilism says that for $X$ to give you a reason to $A$, your $A$-ing has to better promote $X$ than everything else you could do. Actualism says that your $A$-ing just has to better promote $X$ than whatever it is you'd actually do, if you didn't do $A .{ }^{19}$ Probabilism appeals to a kind of expected value, as far as $X$ goes, of not $A$-ing by weighting the degree to which each other option $B$ promotes $X$ by the probability

\footnotetext{
${ }^{19}$ The labels 'Possibilism' and 'Actualism' are familiar from the literature on moral obligation; see Jackson and Pargetter (1986).
} 
that you'll actually perform that option $B .^{20,21}$

Each of these proposals is quite natural. But all of them suffer from the same basic problem. Consider the following simple case, offered by Behrends and DiPaolo (2011). Debbie has a choice between pushing one of three buttons, A, B, and C. If Debbie pushes either $\mathrm{A}$ or $\mathrm{B}$, her desire for $p$ will be satisfied. If she pushes $c$, it will not. Suppose that Debbie actually pushes A, and that if she had not pushed A, she would have pushed B.

According to Possibilism, Debbie's desire that $p$ gave her no reason to push button A, since it did not better promote the object of that desire than something else she could have done, namely pushing button B - either way, her desire that $p$ would have been satisfied.

Similarly, according to Actualism, her desire that $p$ gave her no reason to push button A, since doing so did not better promote the object of the desire than doing what she would have done, had she not pushed button A-namely, pushing button B.

Things are a bit more complicated with Probabilism. But we can describe the case (or at least a similar case) and stipulate some values for the probabilities that Debbie takes each of the options. If we are careful in setting things up, we will be able to describe a case in which, according to Probabilism, Debbie's desire that $p$ again gives her no reason to push button $\mathrm{A}^{22}$

So all three versions of Not $A$, Possibilism, Actualism, and Probabilism, are committed to saying that Debbie's desire that $p$ gave her no reason to push button

\footnotetext{
${ }^{20}$ This view is much more amenable to a probabilistic view of promotion; at the very least, the weighting is straightforward, since we can just calculate the relevant probabilities. Without assuming this probabilistic view, though, it would take some work to spell out just how the weighting will work. Rather than veering way from the main discussion in this way, though, I will trust that the idea is clear enough.

${ }^{21}$ Finlay $(\mathrm{ms})$ gives a kind of Probabilist view, but makes an assumption which he labels the 'Symmetry of Choice', whereby we assume that the agent is equally likely to take each option available to her. Finlay's view will suffer from the same problem as Probabilism, which I'll describe shortly.

${ }^{22}$ If we assume the probabilistic understanding of promotion, here is a counterexample. Suppose the relevant objective is my getting Thai food $(T)$, and there are three options: go to Thai patio, go to RCA, go to Zankou Chicken. Suppose that there is a $60 \%$ chance I go to Thai Patio, a $30 \%$ chance I go to RCA, and a $10 \%$ chance I go to Zankou Chicken. And suppose $P(T \mid$ I go to Thai Patio $)=.9, P(T \mid \mathrm{I}$ go to $\mathrm{RCA})=.2$, and $P(T \mid \mathrm{I}$ go to Zankou Chicken $)=0$. We end up with the result that $P(T \mid \mathrm{I}$ do not go to RCA) is roughly .77, which is greater than $P(T \mid$ I go to RCA $)=.2$. Thus, according to this view, my desire for Thai food gives me no reason at all to go to RCA, even though I clearly have a reason to go to RCA rather than go to Zankou Chicken. Both Actualism and Possibilism will also have problems with this case (assuming I will actually go to Thai Patio if I don't go to RCA). This shows that the argument against those views does not depend on there being ties, as in Behrends and DiPaolo's button-pushing case.
} 
A whatsoever. But clearly this desire gave her a reason to push button A rather than push button $\mathrm{C}$. On a non-contrastive view like Not $A$, though, it is hard to see how Debbie's desire that $p$ could give her a reason to push $\mathrm{A}$ rather than push $\mathrm{C}$ if it gives her no reason whatsoever to push $\mathrm{A}^{23}$ So Not $A$ appears to make it too hard to have reasons to do things - there are cases in which agents clearly have reasons to do $A$ rather than $B$, but this theory - on at least three very natural precisifications - says that the agent has no reason whatsoever to do $A .{ }^{24}$

\subsection{Contrastive promotion}

The lesson to draw from the problems facing the different versions of Not $A$, I suggest, is that the relevant sort of promotion is contrastive. Even if doing $A$ does not better promote some objective than everything else you could do, or even better than what you would actually do if you did not $A$, for example, it can still better promote it than some other option, $B$. What we have seen is that in these cases, the objective clearly gives you reasons to do $A$ rather than $B$. The challenge for the non-contrastivist is to explain how this could be true even though according to those views you have no reason to $A$ whatsoever. The contrastivist, on the other hand, can simply say that you have reasons to do $A$ rather than $B$, even if you don't have reasons to do $A$ rather than some other option $C$. By relativizing reasons to sets that are not necessarily exhaustive of every possibility open to the agent, then, the contrastivist avoids the problems facing non-contrastive theories. In section 4, I will develop this thought into a detailed version of contrastivism.

\subsection{Motivating resolution-sensitivity}

So the arguments against the non-contrastive accounts of reasons in terms of promotion illustrate the advantages of non-exhaustivity. But when I introduced contrastivism in section 1, I pointed out a second feature of the view, namely resolution-

\footnotetext{
${ }^{23}$ See Snedegar (fc) for more thorough (and negative) discussion of various ways the noncontrastivist can try to explain this.

${ }^{24}$ The reader may be wondering about a version of Possibilism on which we replace 'everything' with 'something' - that is, $X$ gives you a reason to $A$ when your $A$-ing better promotes $X$ than something else you can do. This view would avoid the problem facing the three versions of Not $A$ I have considered so far. The argument against this view is slightly more complicated, but the problem will become clear later, when I introduce my own contrastive analysis of reasons for; I'll flag it with a footnote there. To anticipate: the basic problem is that we get many cases in which one and the same consideration is both a reason for and a reason against one and the same action, where both the reason for and the reason against are provided by the same objective. And this is implausible.
} 
sensitivity. The arguments I've given so far don't motivate this feature of contrastivism. But once we relativize reasons to sets of alternatives, there are cases in which whether or not something is a reason for an action seems to depend, not just on what possibilities are covered by the alternatives in the set, but also how we split up those possibilities.

Consider the following version of the famous Professor Procrastinate case from Jackson (1985); Jackson and Pargetter (1986). Professor Procrastinate has been asked to write a review of an important new book, because she is the most qualified person to write it. But she is a terrible procrastinator. If she accepts the invitation, she is very unlikely to actually write the review. And if that happens, the author's career and the field at large will suffer. If Procrastinate just declines the invitation, someone else - less qualified, but more reliable - will be asked to write, and will do so. In this case, the fact that Procrastinate is a procrastinator is a reason for her to decline the invitation rather than accept. That is, it's a reason to decline out of \{decline, accept\}, plausibly provided by the objective of doing what's best for the profession. But it is intuitively not a reason to decline out of the more fine-grained set, $\{$ decline, accept and write, accept and don't write $\} .{ }^{25}$ So whether or not this fact is a reason to decline seems to depend on the resolution at which we divide up the alternatives. Thus, once we relativize reasons to sets of alternatives, there's good reason to allow the sets to vary in resolution, rather than, say, making them all maximally fine-grained. ${ }^{26}$

\section{Contrastive Reasons and Promotion}

I have argued that the relationship between reasons and promotion is best understood contrastively. An objective can give you reasons to perform an action $A$ relative to a set of alternatives when your $A$-ing promotes that objective better than anything else in the set. In this section, I will begin to develop this idea into a more detailed contrastive account of reasons.

Promote tells us what has to hold for you to have a reason to $A$, or for there to be a reason for you to $A$. But we want an account of when some fact is a reason for you

\footnotetext{
${ }^{25}$ Remember that the option is 'accept and write', not 'try to accept and write' or 'agree to accept and write'. And by hypothesis, accepting and writing is better than declining, even if accepting is not better than declining. This is what is interesting and somewhat puzzling about this case, and why it motivates resolution-sensitivity.

${ }^{26} \mathrm{As}$ I pointed out in footnote 4 above, this is consistent with saying that some reasons are relativized to special sets, perhaps sets that are divided up in ways that make all important moral distinctions, for example.
} 
to $A$. Philosophers who appeal to promotion to analyze the reason relation frequently appeal to explanation here. If you have a reason to $A$ because $A$-ing promotes some objective, then some fact is a reason for you to $A$ when it explains why (or is an essential part of the explanation for why) $A$-ing promotes the objective. ${ }^{27}$ I have a reason to go to the store because doing so would promote the objective of my having breakfast in the morning. The fact that I'm out of milk is part of the explanation for why going to the store would promote this objective. So according to this idea, the fact that I'm out of milk is a reason to go to the store. I'll adopt this strategy here.

So what we want is a contrastivist analysis of reasons for and reasons against in terms of promotion. So far I have said that $r$ is a reason for you to $A$ out of $Q$ when it helps explain why your $A$-ing would promote some objective better than other alternatives in $Q$. Conversely, it is natural to think that $r$ is a reason against $A$-ing out of $Q$ when it helps explain why $A$-ing would promote some objective less well than other alternatives in $Q$.

First a quick note about reasons against. It is often thought that a reason against some action $\phi$ is just a reason for not- $\phi{ }^{28}$ On this view, we can just have one kind of reason, reasons for. But the contrastivist cannot accept this view because, given non-exhaustivity, the sets of alternatives reasons are relativized to need not be closed under negation: just because $\phi$ is in a set, it does not follow that not- $\phi$ is also in the set. So if we want to talk about reasons against an alternative $\phi$ relative to a set $Q$, we can't just talk about the reasons for not- $\phi$ out of $Q$, since not- $\phi$ might not even be in $Q$. Thus, the contrastivist needs to define reasons against-reasons not to $\phi$, instead of reasons to not- $\phi$ - separately.

So start (for expositional purposes) with reasons against. I suggest the following analysis:

Against: $r$ is a reason against $A$-ing out of $Q$ iff there's some $X$ of the relevant kind ${ }^{29}$ such that $r$ explains why ${ }^{30} B$-ing better promotes $X$ than $A$-ing, for some other

\footnotetext{
${ }^{27}$ For analyses of reasons partly in terms of explanation, see Toulmin (1950); Broome (2004); Searle (2001); Finlay (2001, 2006, ms); Schroeder (2007). Like these other writers (with the possible exception of Finlay), I take the relevant sort of explanation here to be a non-epistemic notion. For $r$ to explain why your $A$-ing would promote $X$ is for $r$ to be part of what makes it true that your $A$-ing would promote $X$.

${ }^{28}$ See Nagel (1970), footnote 1 on p. 47, for example.

${ }^{29} \mathrm{By}$ 'some $X$ of the relevant kind', I mean the following: there's some set of objectives that are the things to be promoted, according to our theory of reasons. A desire-based theory will say that this set contains objects of the desires of the agent; a value-based theory will say that it contains some independent values. $X$ is an objective of the relevant kind when it is in this set. By existentially quantifying here, we allow that there are multiple objectives that can give you reasons in any individual case.

${ }^{30} \mathrm{Or}$ is part of the explanation of why-I'll ignore this qualification from now on.
} 
alternative $B$ in $Q \cdot{ }^{31}$

If you could do better, as far as $X$ is concerned, by doing something other than $A$ ing, then $X$ very plausibly gives you a reason against $A$-ing. An obvious alternative to Against would say that your $A$-ing has to do worse at promoting $X$ than all the other alternatives. But this misses out on some intuitive reasons against. For example, suppose I can travel the 15 miles to campus by jogging, biking, or driving. The fact that I want to get there in under an hour intuitively gives me a reason against biking, even though I have a better chance of getting there in under an hour if I bike than if I jog-it's still quite unlikely that I get there in under an hour if I bike.

Once we accept Against as an analysis of reasons against, I think we should accept the following analysis of reasons for:

For: $r$ is a reason for you to $A$ out of $Q$ iff there's some $X$ of the relevant kind such that $r$ explains why $A$-ing better promotes $X$ than $B$, for all the other alternatives $B$ in $Q \cdot{ }^{32,33}$

This makes reasons for harder to come by than reasons against. But I think this is a very plausible analysis of reasons for. If you could do better, as far as $X$ is concerned, by doing something other than $A$-ing, it would be strange if $X$ gave you a reason to $A$ out of a set of alternatives that includes that other thing.

The most natural alternative would say that $X$ can give you a reason to $A$ relative to some set when your $A$-ing would better promote $X$ than some other alternative in the set. This would capture the reasonable idea that a consideration can be a reason for multiple members of the same set, but just a weightier reason for those that better

\footnotetext{
${ }^{31}$ Here is the version we would get if we assumed the popular probability-raising view of promotion:

Against Prob: $r$ is a reason against $\phi$-ing out of $Q$ iff there's some $X$ of the relevant kind such that $r$ explains why $P(X \mid$ you $A)<P(X \mid$ you $B)$, for some other alternative $B$ in $Q$.

${ }^{32}$ Interestingly, though I reject Finlay (ms)'s non-contrastive account of reasons, this contrastive account of reasons for closely mirrors his contrastive analysis of 'ought'. According to that analysis, roughly, you ought to $A$ just in case your $A$-ing makes the contextually salient end more likely than any other relevant alternative. By allowing multiple objectives - the analog of Finlay's ends - to provide reasons in a single context, my analysis is better suited to the pro tanto notion of a reason.

${ }^{33}$ Probabilistic version:
}

For Prob: $r$ is a reason for you to $\phi$ out of $Q$ iff there's some $X$ of the relevant kind and $r$ explains why $P(X \mid$ you $\phi)>P(X \mid$ you $\psi)$, for all $\psi \neq \phi$ in $Q$. 
promote the relevant objective. ${ }^{34}$ But if we accept this in addition to Against, we get the following problem. Some consideration $r$ could be both a reason for and a reason against all the alternatives in the middle - that do not do the best and that do not do the worst, in terms of promoting $X$. For example, in the case I introduced above, the fact that campus is fifteen miles away would be both a reason to bike and a reason not to bike, both provided by my desire to get to campus in under an hour. But it's implausible that one and the same consideration can be both a reason for $A$ and against $A$, both provided by some single objective $X{ }^{35}$

A concern about this picture involves cases in which two alternatives from a set do an equally good job promoting a given objective. Suppose that some objective $X$ would be equally well promoted either by $A$-ing or by $B$-ing. According to For, $X$ does not give me any reason to $A$ or any reason to $B$, relative to a set that includes both, like $\{A, B, C\}$. This is a bit counterintuitive; it seems that $X$ could give us reasons for both $A$ and $B$, rather than neither. This suggests replacing For with a principle which says that $r$ is a reason for $A$ out of $Q$ when $A$ promotes some objective at least as well as any other member of $Q$. The primary reason I do not adopt this principle is that it does not allow us to capture all of the entailment relations between reasons relative to different sets that I think we need to capture.

Moreover, I think we can mitigate the counterintuitiveness of the claim that, when $A$ and $B$ equally well promote some objective, that objective doesn't provide reasons for either of them relative to a set that includes both. First, it is not at all counterintuitive to deny that the objective provides reasons for $A$ rather than $B$ (or for $B$ rather than $A$ ) - that is, for $A$ (or $B$ ) relative to $\{A, B\}$. And this is because $A$ and $B$ do an equally good job promoting the objective. So perhaps it is not so bad to say that it does not provide reasons for $A$ out of $\{A, B, C\}$. After all, you could just as easily promote the objective by doing $B$ instead, and $B$ is a relevant alternative. ${ }^{36}$

\footnotetext{
${ }^{34}$ I want to emphasize here that For and Against are accounts of when some consideration is a reason for an action; for all I have said, they have nothing at all to say about the weight of those reasons, or what you have most reason to do. Providing an account of weight for contrastive reasons is an important part of a larger project, but it is not one I can take up here.

${ }^{35}$ I think that one consideration can be both a reason to $A$ and a reason not to $A$ (relative to the same set of alternatives). But I don't think that both of these can be provided by the same objective (desire, end, or value). Many popular theories of reasons cannot allow for cases like this. For example, Schroeder (2007)'s Hypotheticalism rules them out, since it cannot be that the object one and the same desire is promoted both by $A$-ing and by not $A$-ing, given any reasonable understanding of promotion. See Snedegar (fc) for more thorough discussion of this point. This argument also tells against a revised version of Possibilism, mentioned in footnote 24, according to which an objective provides a reason for you to $A$ when $A$-ing better promotes an objective than something - instead of everything - else you could do.

${ }^{36}$ We may add that $A$ must also do better than some member of $Q$, to avoid saying that $r$ is a
} 
Second, the objective does provide both reasons for $A$ rather than $C$ and for $B$ rather than $C$. Third, given Against, the objective gives you reasons against $C$ out of $\{A$, $B, C\}$, but does not give you reasons against either $A$ or $B$. And finally, as we will see later, on my view, we can say that the objective gives you reasons for $A \vee B$ out of the closely related set, $\{A \vee B, C\}$. Given these considerations, and the fact that the suggested replacement for For misses out on some intuitive entailment relations that For can capture, I will stick with the For formulation.

Another potential objection to this view is that its treatment of reasons against is too liberal. A reason against some alternative, you might think, has to "imply a significant criticism" of that alternative, to borrow a phrase from Greenspan (2005, 2007), and merely being a reason for an incompatible alternative isn't enough. But other philosophers seem to agree with me that a reason for one alternative is in fact a reason against other incompatible alternatives, for some relatively weak notion of incompatibility, like physical or psychological incompatibility. ${ }^{37}$ If some consideration $r$ is a reason for $A$-if it highlights some benefit of doing $A$ - and if doing $B$ precludes doing $A$, then it is very plausible that $r$ is a reason against $B$, since doing $B$ would keep you from getting that benefit. This is just the familiar notion of an opportunity cost: among the costs of - or reasons against - choices you make are the benefits you sacrifice that would come from making other choices.

Note, though, that we can draw an interesting distinction between two types of reasons against on this view. A reason against some alternative that does imply a significant criticism of that alternative - like the fact that Zankou Chicken is really crowded at this time of day - often won't turn out to be a reason for any other particular alternative. That's because these sorts of facts are often irrelevant for differences between other alternatives in the set. For example, the fact that Zankou Chicken is really crowded doesn't tell us anything about the relationship between going to Thai Patio and going to Spicy Thai BBQ. So it doesn't explain why either going to Thai Patio better promotes my desire not to wait than going to Spicy Thai BBQ, or vice versa. So by For, it won't turn out to be a reason for either of these, though it's still

reason to $A$ rather than $B$ (or to $A$ out of $\{A, B\}$ ) when $A$ and $B$ promote the relevant objective equally well. But the point is just that, since the objective does not provide reasons relative to $\{A$, $B$, perhaps it isn't so bad to deny that it provides reasons relative to larger sets that include both $A$ and $B$.

${ }^{37}$ Sinnott-Armstrong (2008) says that a reason "favors one thing and disfavors others" (p. 258). Ruben (2009) says that when doing $A$ is incompatible with doing $B$, "a reason to do an act of type $B$ must also be a reason not to do an action of type $A$ " (p. 63). And Broome (2013) cites nice features of one alternative - which are reasons for taking that alternative - as reasons against incompatible alternatives. See the Montreux-Marrakesh example on p. (???). Compare also the discussion of 'General Substitutability' in Sinnott-Armstrong (1992), section 1. 
a reason against going to Zankou Chicken. Reasons against an alternative that do not imply a significant criticism, on the other hand, will often be reasons for other particular alternatives. So, even on this view, we can capture Greenspan's insight: some considerations merely count against certain alternatives without counting in favor of others.

\section{$5 \quad$ Providing the Constraints}

In this section, I'll show that the theory I developed in the last section, independently motivated by considerations about the relationship between reasons and promotion, straightforwardly provides the constraints on the independence of reasons relative to different sets of alternatives I motivated in section 2, as well as some other interesting and intuitive constraints.

\subsection{Transitivity}

The first constraint we need on the independence of reasons relative to different sets is one that rules out intransitivity. That is, we want it to turn out that whenever $r$ is a reason for $A$ rather than $B$ and for $B$ rather than $C$, it is also a reason for $A$ rather than $C$. In fact, we need an importantly but subtly different constraint, once we adopt a view on which we explain reasons in terms of the promotion of various kinds of objectives. We don't just want reasons for $A$ rather than $B$ and for $B$ rather than $C$ to be reasons for $A$ rather than $C$; we want them to be provided by the same objective. A case in which my desire for Thai food gives me a reason $r$ for $A$ rather than $B$ and for $B$ rather than $C$, but not for $A$ rather than $C$ is counter to the transitivity intuition, even if, say, my desire to spend lots of money explains why $r$ is a reason for $A$ rather than $C$.

So what we need is the following kind of constraint:

Transitivity: If $r$ is a reason for $A$ rather than $B$, provided by $X$, and a reason for $B$ rather than $C$, provided by $X$, then $r$ is a reason for $A$ rather than $C$, provided by $X$.

Fortunately, it is easy to see that this follows straightforwardly from the framework I developed in the last section. Recall the minimal assumptions I am making about the

promotion relation relevant for Promote - for an analysis of reasons. In particular, I am assuming that the promotion relation ranks alternatives in terms of how well they 
promote a given objective (so each objective gives us a different promotion ranking); this ranking, I assumed, is transitive. ${ }^{38}$ Thus, if $A$ better promotes $X$ than $B$, and $B$ better promotes $X$ than $C$, then $A$ better promotes $X$ than $C$. And given plausible assumptions about how explanation works in these cases - namely, that if $r$ explains both why $A$ better promotes $X$ than $B$ and why $B$ better promotes $X$ than $C$, then it also explains why $A$ better promotes $X$ than $C-r$ explains this. ${ }^{39}$ Finally, given For, Transitivity follows.

\subsection{Non-exhaustivity}

Now I'll discuss other entailments between reasons relative to sets that differ in the alternatives they include - that is, sets that differ along the dimension of nonexhaustivity.

First, consider reasons for an alternative relative to one set, and reasons for that alternative relative to a subset of that initial set. I said above that intuitively, facts which are reasons for $A$ relative to $Q$ should also be reasons for $A$ relative to subsets of $Q$ that contain $A$. Suppose that this were not true. Then there might be a case in which $r$ is a reason for $A$ rather than either of $B$ or $C$, but not a reason for $A$ rather than $B$. It's implausible that there could be such a case, so we should rule it out.

Fortunately, the theory I developed in the last section - in particular For - delivers precisely this result. If $r$ is a reason for $A$ out of $Q$, provided by objective $X$, then by For, $r$ explains why $A$ better promotes $X$ than $B$, for all the other alternatives $B$ in $Q$. Since the degree to which actions promote objectives does not vary with the alternatives, $A$ will better promote $X$ than $B$ for all the alternatives $B$ in any subset of $Q$. Given the same kinds of assumptions as those we made above about explanation, $r$ will explain this. So $r$ will be a reason for $A$ out of any subset of $Q$ that contains $A$.

Next, consider reasons against. I said above that reasons against an alternative out of one set should also be reasons against that alternative out of supersets of the initial set. If this entailment did not hold, then we might have a case like the following. $r$ is a reason against $A$ when the alternative is $B$ alone, but not a reason against $A$ when we consider $C$ in addition to $B$. Again, this is implausible.

\footnotetext{
${ }^{38}$ As I pointed out above, the popular probability-raising view of promotion gives us this property, simply because the greater than relation is transitive. We can see this clearly by looking at the probabilistic version of For given in footnote 33.

${ }^{39}$ Remember that I'm using a non-epistemic notion of explanation here. Perhaps the epistemic notion will not have this feature, but the sense I intend, on which $x$ explains $y$ when $x$ is part of what makes it true that $y$, does.
} 
Fortunately, the theory delivers just the result we want. Suppose $r$ is a reason against $A$ out of $Q$, explained by $X$. Then, by Against, some other alternative in $Q$ better promotes $X$ than $A$. Merely adding some new alternatives to $Q$ won't change this fact: the alternatives that better promote $X$ than $A$ will still do so. Thus, $r$ will also be a reason against $A$ relative to the new superset of $Q$. So the independently motivated version of contrastivism that analyzes reasons in terms of promotion delivers precisely the constraints we need, on the independence of reasons relative to sets and their subsets and supersets.

\subsection{Resolution-sensitivity}

I also introduced a second feature of contrastivism, which I labeled resolution-sensitivity. Two sets of alternatives may cover the same possibilities, but do so at different levels of detail. For example, we might have reasons to $A$ relative to a more fine-grained set like $\{A, B, C\}$ or relative to the more coarse-grained set $\{A, B \vee C\}$. The second set divides up the possibilities in a more coarse-grained way, by grouping together the $B$ and $C$ possibilities. Now I will suggest that there should be constraints on how reasons can vary as the resolution differs, and show that the theory I have developed delivers them.

Suppose the fact that I don't have any vacation days left is a reason to go to work out of go to work, stay home and clean, stay home and watch TV, stay home and do something else\}, explained by my desire not to get fired. Then it is also a reason to go to work out of the more coarse-grained set $\{$ go to work, stay home $\}$. If $\operatorname{doing} A$ is better, with respect to the objective $X$, than all of the (relevant) ways of doing $B$, then doing $A$ is obviously better than doing $B$, as far as $X$ is concerned. So reasons for an alternative out of one set should also be reasons for that alternative out of sets that group together the other alternatives, resulting in a more coarse-grained set.

Next, consider reasons against. The fact that I am out of vacation days is a reason against staying home out of the relatively coarse-grained set, \{go to work, stay home\}. It is also a reason against staying home out of the more fine-grained set, \{go to work by car, go to work by bus, go to work some other way, stay home\}. So reasons against an alternative out of one set should also be reasons against that alternative out of sets that separate the other alternatives into more fine-grained alternatives.

Recall that, in addition to the assumption that the promotion relation provides us with a ranking of alternatives, I also assumed that the ranking has a special property called Disjunction Boundedness: 
Disjunction Boundedness: For all actions $A$ and $B$ and for all objectives $X, A \vee B$ is ranked somewhere between (inclusive) $A$ and $B$, in terms of how well it promotes $X$.

The intuitive thought here is simply that doing $A \vee B$ cannot do better than both $A$ and $B$, or worse than both $A$ and $B$, at promoting a given objective - doing $A \vee B$ requires doing one or the other, after all. So I think this is a very safe assumption. ${ }^{40}$

Fortunately, this safe assumption is just what we need to secure the entailment relations between reasons relative to sets that differ in resolution. When $r$ is a reason for $A$ out of $\{A, B, C\}$, provided by $X$, that means it better promotes $X$ than either $B$ or $C$, by For. Given Disjunction Boundedness and For, then, $r$ will also be a reason for $A$ out of the more coarse-grained set $\{A, B \vee C\}$.

Suppose that $r$ is a reason against $A$ out of $\{A, B\}$. That means it does a worse job promoting $X$ than $B$. Now suppose we divide $B$ into more fine-grained alternatives, say $C$ and $D$, to obtain the more fine-grained set $\{A, C, D\}$, where $B=C \vee D$. We know by Disjunction Boundedness that $B$ cannot be ranked below both of $C$ and $D$. Since $A$ is ranked below $B$, then, $A$ must be ranked below at least one of $C$ and $D$. So by Against, $r$ will be a reason against $A$ out of $\{A, C, D\}{ }^{41}$

I've shown that the contrastive theory of reasons I developed in the last section straightforwardly provides just the right constraints on the independence of reasons relative to different sets. Though I don't have the space to explore them here, the theory also provides other interesting constraints that are less obvious, but no less intuitive, once they're in view, than the ones I've discussed. I take this to provide additional confirmation for the theory, since it not only provides the obvious constraints, but also brings others into view. ${ }^{42}$

\footnotetext{
${ }^{40} \mathrm{As}$ I pointed out above, the popular probability-raising view of promotion gives us this property, because it is a fact about conditional probability that, where $P(X \mid A)>P(X \mid B)$, $P(X \mid A) \geq P(X \mid A \vee B) \geq P(X \mid B)$.

${ }^{41}$ We might also wonder about the relationship between reasons for $A$ relative to one set and reasons for more coarse-grained alternatives that subsume $A$ (say, $A \vee B$ ) in more coarse-grained sets of alternatives. Similarly, we might wonder about the relationship between reasons for a more coarse-grained alternative (say, $A \vee B$ ) and reasons for the fine-grained alternatives that it subsumes (say, $A$ ) relative to more fine-grained sets. It turns out that the theory doesn't deliver any constraints in these cases. I think these are the intuitively correct results, though I won't argue for that here.

${ }^{42}$ In particular, we get entailments between reasons for and against relative to unions and intersections of those sets.
} 


\section{Non-Promotional Reasons}

So far, I have argued that the widespread idea that reasons involve promotion supports a particular version of contrastivism that delivers intuitive constraints on how reasons can vary with the alternatives. In doing so, I have assumed that all reasons involve promotion of the sort I have been discussing. In this section I will show how to relax that assumption.

In section 2, I argued that even if we think that some reasons do not involve promotion, but rather involve respecting or honoring values, my argument that the reasons that do involve promotion are contrastive puts rational pressure on us to adopt contrastivism about all reasons. But there is still a serious gap. I've spent the last few sections showing how a contrastive theory of reasons cashed out in terms of promotion straightforwardly delivers important constraints on how reasons can vary with sets of alternatives. In doing so, I made crucial use of rankings of alternatives in terms of how well they promote various objectives. But if some reasons do not involve the promotion of objectives at all, how can we provide the constraints for these reasons? Moreover, if we need to tell some other story for these reasons, there's a worry that it will generalize to explain the constraints on how the reasons that do involve promotion can vary. This would undermine my claim that the idea that reasons involve promotion and contrastivism about reasons provide an attractive mutually supporting package.

Fortunately, I think we can generalize the explanation of the constraints given in terms of promotion. The basic idea is that different alternatives can do better or worse at respecting or honoring values. For example, going into the burning building to save someone does better at respecting the value of human life than merely calling 911, which in turn does better than just walking by without even calling 911. There may be various ways of being better at respecting or honoring some value. For example, one action may respect a given value more than another action, or one action may be closer to the ideal way of honoring a given value than another action. The important point is that we will still be able to get a ranking of alternatives, not in terms of how well they promote a given value, but in terms of how well they respect or honor that value. ${ }^{43,44}$ And this ranking will very plausibly have the Disjunction Boundedness

\footnotetext{
${ }^{43}$ Some rankings will likely be pretty uninteresting, with one alternative at the top and all other alternatives tied at the bottom, as not respecting the value at all. For example, if I promise to $A$, then a ranking of the alternatives $\{A, B, C, D\}$ in terms of how well they respect the value of promise-keeping will be trivial in this way.

${ }^{44}$ It's possible that these non-promotional rankings will more often involve ties and incommensurability, since there are often plausibly different but equally or incommensurably good ways of
} 
property. If so, we will be able to appeal to these rankings in providing constraints on how non-promotional reasons can vary between sets of alternatives. To take just one example, if some fact $r$ explains why $A$ does a better job at respecting value $V$ than $B$ does, and why $B$ does better than $C$, it will likewise explain why $A$ does better than $C$. So we can see how the Transitivity constraint can be captured.

So the assumption that all reasons involve promotion is not necessary for my purposes here. As long as we agree that some reasons involve promotion, my argument for contrastivism will go through. And as I pointed out above, this puts pressure on us to adopt contrastivism about all reasons, even those that do not involve promotion. Finally, I have just shown how to capture the constraints on how reasons can vary for reasons that do not involve promotion.

\section{Conclusion}

In this paper, I've shown that an independent source of motivation for contrastivismthe relationship between reasons and promotion - leads very naturally to a version of the theory that straightforwardly solves an important problem for the contrastivist. By appealing to this idea, we can capture intuitive relationships between reasons relative to different sets of alternatives without sacrificing the independence that lets the contrastivist solve problems facing non-contrastive theories. The upshot, then, is that one of the most compelling sources of motivation for contrastivism about reasons generates what I take to be the most attractive and most defensible version of the theory.

\section{References}

Anderson, E. (1993). Value in Ethics and Economics. Harvard University Press.

Baron, M., Pettit, P., and Slote, M. (1997). Three Methods of Ethics: A Debate. Blackwell Publishers.

Bedke, M. (ms). Ends to means: Transmitted reasons and their weights. Unpublished manuscript, University of British Columbia.

Behrends, J. and DiPaolo, J. (2011). Finlay and Schroeder on promoting a desire. Journal of Ethics and Social Philosophy.

Broome, J. (1991). Weighing Goods. Blackwell Publishers.

respecting some value. This is no problem for the view I'm developing. 
Broome, J. (2004). Reasons. In Wallace, Pettit, Scheffler, and Smith, editors, Reason and Value: Themes from the Moral Philosophy of Joseph Raz, pages 28-55. Oxford University Press.

Broome, J. (2013). Rationality Through Reasoning. Wiley-Blackwell.

Cariani, F. (2013). 'Ought' and resolution semantics. Noûs, 47(3):534-558.

Dancy, J. (2004). Ethics Without Principles. Oxford University Press.

Evers, D. (2009). Humean agent-neutral reasons? Philosophical Explorations, $12(1): 55-67$.

Finlay, S. (2001). What Does Value Matter? The Interest-Relational Theory of the Semantics and Metaphysics of Value. PhD thesis, University of Illinois, UrbanaChampaign.

Finlay, S. (2006). The reasons that matter. Australasian Journal of Philosophy, 84(1):1-20.

Finlay, S. (ms). Confusion of Tongues. Unpublished book manuscript.

Friedman, A. (2009). Intransitive ethics. Journal of Moral Philosophy, 6:277-297.

Greenspan, P. (2005). Asymmetrical practical reasons. In Reicher, M. and Marek, J., editors, Experience and Analysis: Proceedings of the 27th International Wittgenstein Symposium, pages 387-394. oebv\&hpt.

Greenspan, P. (2007). Practical reasons and moral 'ought'. In Shafer-Landau, R., editor, Oxford Studies in Metaethics, volume 2, pages 172-194. Oxford University Press.

Jackson, F. (1985). On the semantics and logic of obligation. Mind, 94(374):177-195.

Jackson, F. and Pargetter, R. (1986). Oughts, options, and actualism. Philosophical Review, 95(2):233-255.

Kierland, B. (ms). A new approach to the future dependence issue. Unpublished manuscript, Boise State University.

Kolodny, N. (ms). Instrumental reasons. Unpublished manuscript.

Moore, G. (1903). Principia Ethica. Cambridge University Press.

Moore, G. (1912). Ethics. Williams \& Norgate.

Nagel, T. (1970). The Possibility of Altruism. Princeton University Press.

Norcross, A. (2005). Contextualism for consequentialists. Acta Analytica, 20(2).

Parfit, D. (2011). On What Matters. Oxford University Press. 
Pettit, P. (1991). Consequentialism. In Singer, P., editor, A Companion to Ethics, pages 230-237. Blackwell Publishers.

Rachels, S. (1998). Counterexamples to the transitivity of 'better than'. Australasian Journal of Philosophy, 76(1):71-83.

Rachels, S. (2001). A set of solutions to Parfit's problems. Noûs, 35:214-238.

Ross, J. (2006). Acceptance and Practical Reason. PhD thesis, Rutgers University.

Ruben, D.-H. (2009). Con-reasons as causes. In Sandis, C., editor, New Essays on the Explanation of Action, pages 62-74. Palgrave Macmillan.

Scanlon, T. (1998). What We Owe to Each Other. Harvard University Press.

Schroeder, M. (2007). Slaves of the Passions. Oxford University Press.

Searle, J. (2001). Rationality in Action. MIT Press.

Sinnott-Armstrong, W. (1992). An argument for consequentialism. Philosophical Perspectives, 6:399-421.

Sinnott-Armstrong, W. (2004). Classy Pyrrhonism. In Sinnott-Armstrong, W., editor, Pyrrhonian Skepticism. Oxford University Press.

Sinnott-Armstrong, W. (2006). Moral Skepticisms. Oxford University Press.

Sinnott-Armstrong, W. (2008). A contrastivist manifesto. Social Epistemology, $22(3): 257-270$.

Snedegar, J. (2013). Contrastive Reasons. PhD thesis, University of Southern California.

Snedegar, J. (fc). Reason claims and contrastivism about reasons. Philosophical Studies.

Temkin, L. (1987). Intransitivity and the Mere Addition Paradox. Philosophy and Public Affairs, 16(2):138-187.

Temkin, L. (2012). Rethinking the Good: Moral Ideals and the Nature of Practical Reasoning. Oxford University Press.

Toulmin, S. (1950). Reason in Ethics. Cambridge University Press.

Wedgwood, R. (2009). Intrinsic values and reasons for action. Philosophical Issues, 19:342-363.

Yalcin, S. (2011). Nonfactualism about epistemic modality. In Egan, A. and Weatherson, B., editors, Epistemic Modality. Oxford University Press. 